\title{
CARACTERISTICAS DENDROLOGICAS DE CINCO ESPECIES FORESTALES DE SELVA BAJA
}

Juan R. Baluarte Vásquez*

\section{RESUMEN}

En el presente estudio, se efectuó la descripción de las características dendrológicas de cinco especies forestales de Jenaro Herrera, ubicado en la zona de vida, bosque húmedo tropical.

En adición a estas características, se menciona algunas particularidades de la estructura leñosa, propiedades físicas y mecánicas, así como el comportamiento a las máquinas de carpintería. Con el propósito de ampliar el conocimiento de estas especies se acompaña algunas observaciones sobre su autoecología.

La característica más destacable del presente trabajo es la descripción de especies poco informadas en anteriores estudios.

\section{SUMMARY}

This paper describes the dendrological characteristics of five species of trees studied at Jenaro Herrera, in the Tropical humid forest life zone. Details of the wood structur and physical and mechanical properties, as well as on the performance of carpentry machinery, are also dealt with. Autecological observations on these species are included. This study focused on species that have received only little previous attention.

Palabras Claves: Dendrología, tecnología, usos, autoecología, especies forestalesselva baja.

\section{INTRODUCCION}

El enorme potencial presente en los bosques amazónicos de selva baja, representa sin lugar a dudas un reto para todos los peruanos. No obstante conocidas son las razones que han venido dificultando su plena incorporación al desarrollo regional; muchas de ellas se refieren a la dificultad de su aprovechamiento por las condiciones propias de estos bosques, así como por el desconocimiento del recurso mismo en los aspectos taxonómicos y dendrológicos. Cabe indicar, especialmente, la poca importancia que se le ha dado a es te campo; lo cual no permite orientar adecuadamente su aprovechamiento, muy ligado cada una de ellos a la escasez de recursos económicos.

* Director General de Investigación Forestal y Fauna-IIAP. 
Teniendo en cuenta un sin número de limitaciones para identificar nuestras especies forestales, corno la falta de equipos de laboratorio, carencia de material bibliográfico para consulta, etc.; la identificación basada en las características dendrológicas constituye una alternativa válida para superar estas dificultades.

El presente estudio pretende contribuir al conocimiento de la flora amazónica, utilizando esta ciencia y poniendo al alcance de la comunidad científica y usuarios en general las características dendrológicas de cinco especies forestales poco estudiadas de la región.

Sobre estas cinco especies, desde el punto de vista florístico, informaron Spichiger et al. 1989 y 1990. El presente estudio fue registrado durante el desarrollo del Proyecto "Estudios básicos y aplicados de maderas del bosque húmedo Tropical", ejecutado en la localidad de Jenaro Herrera ubicado en la margen derecha del río Ucayali, a $200 \mathrm{Km}$. de Iquitos.

\section{MATERIALES Y MÉTODOS}

\section{LOCALIZACIÓN DE LA ZONA DE ESTUDIO}

Este trabajo se efectuó en el distrito de Jenaro Herrera, ubicado en la margen derecha del río Ucayali, Provincia de Requena, Departamento de Loreto, Perú. Geográficamente está sobre coordenadas $04^{\circ} 55^{\prime} \mathrm{LS}$ y $73^{\circ} 40^{\prime} \mathrm{LW}$. El área específica corresponde al bosque denominado "El Copal", ubicado a $12.4 \mathrm{Km}$. al Este de Jenaro Herrera; la altura media es de $160 \mathrm{msnm}$, los tipos de suelos predominantes corresponden a los de ultisol, alfisol e inceptisol (Sabogal 1980).

De acuerdo a la clasificación de UNESCO (1981), basada en las características ecológicofisionómicas de las formaciones vegetales, considera a esta formación como bosque ombrófilo tropical de baja altitud; más preciso, es la información de ONERN (1976), basada en la clasificación de Holdridge (1987), ambas tipifican a este lugar como zona de vida natural "bosque húmedo tropical". La información climatológica analizada por Marengo (1983) correspondiente a un período de 10 años es la siguiente: temperatura media anual $25.90^{\circ} \mathrm{C}$ precipitación promedio anual $2,888 \mathrm{~mm}$ y humedad relativa de $87 \%$.

\section{PROCEDIMIENTO}

El presente estudio se efectuó como parte del proyecto "Estudios básicos y aplicados de maderas del bosque húmedo tropical", correspondiéndole al autor de este artículo la responsabilidad de la colecta e identificación del material de campo; por esta razón se cuenta con abundante información que será expuesta en este documento. 
Se contó con abundante material y equipos de campo, los que han permitido profundizar los aspectos descriptivos poco informados por anteriores estudios de esta naturaleza. Es así como, luego de ubicar 5 árboles de la misma especie, fueron medidos el diámetro a la altura del pecho con una forcípula, luego los árboles fueron apeados con una motosierra, procediendo de inmediato con cinta métrica a registrar las mediciones correspondientes a la altura total del árbol, del fuste, tamaño de la copa, etc.

La información dendrológica fue vaciada en un formulario tomado de Ríos (1982). Esta información fue compatibilizada con los 5 árboles a fin de no excluir ninguna característica relevante; asimismo, se procedió a observar el corte transversal del fuste en estado húmedo, resaltando los detalles referentes a la conformación de la sección transversal, olor, color, forma de la albura, duramen y médula.

Todo esto fue complementado con el comportamiento de la madera al aserrío, ya que las muestras de madera para los ensayos tecnológicos fueron obtenidos in situ con un aserradero artesanal confeccionado en base a una motosierra.

De cada uno de los 5 árboles se procedió a la colecta de una muestra botánica para la identificación taxonómica, esta labor se desarrolló con el a poyo de material bibliográfico y su respectiva confrontación con las excicatas del Herbario de la Universidad Nacional de la Amazonía Peruana, lugar donde se encuentran actualmente depositados estos ejemplares.

\section{RESULTADOS Y DISCUSIONES}

\section{IDENTIFICACIÓN DE LAS ESPECIES ESTUDIADAS}

Los resultados de la identificación taxonómica se presentan en el cuadro 1 . 


\section{Cuadro 1}

\section{IDENTIFICACIÓN TAXÓNOMICA DE LAS CINCO ESPECIES FORESTALES.}

\begin{tabular}{lll}
\hline $\begin{array}{l}\text { Nombre científico } \\
\begin{array}{l}\text { Osteophloeum platyspermurn } \\
\text { (A.DC.) Warb. }\end{array}\end{array}$ & Familia & Nombre común \\
$\begin{array}{l}\text { Qualea paraensis } \\
\text { caspi. }\end{array}$ & Ducke & Vochysiaceae \\
$\begin{array}{l}\text { Qualea trichanrhera Warm. } \\
\text { Tapirira guianensis Aublet. } \\
\text { Vantanea parviflora Lamb. }\end{array}$ & Vochysiaceae & $\begin{array}{l}\text { Favorito, cumala } \\
\text { blanca. }\end{array}$ \\
\hline
\end{tabular}

\section{DESCRIPCIÓN DE LAS ESPECIES ESTUDIADAS}

Osteophloeum platyspermurn (A. DC.) Warb (gráfico 1).

Árbol dominante, con fuste recto y cilíndrico desde el suelo hasta la primera rama. Presenta una arquitectura muy típica, siguiendo el modelo de Massart, muchas veces con "reiteraciones" (Hallé et al., 1978), citado por Spichiger (1982).

Corteza externa esponjosa, marrón claro humoso; ritidoma desprendihle en tiras largas rectangulares o irregulares. Corteza interna fibrosa, amarillenta; exuda abundante savia amarillo-ambar cristalino, olor característico y sabor astringente.

Ramita terminal cilíndrica, color oscuro, comprimida en la punta, asurcada y densamente puberulenta.

Hojas simples, alternas y decusadas; coriácea; haz glabra; limbo de forma obovada, ápice redondeado a veces emarginado; pecíolos esbeltos, puberulentos como las ramitas, canaliculados, base obtusa o aguda; borde entero, revoluto; nervio medial impreso canaliculado en la haz, muy prominente en el envés, 7-8 nervios laterales broquidódromos, muy delgados en ambas caras, rectos y ascendentes.

Inflorescencia diminuta, paniculada de $1.0-5.0 \mathrm{~cm}$., también puberulento, pedúnculo pardo marrón. Flores solitarias o en fascículos de 2-8, con bractéolas deciduas en la base, pedicelos con bractéolas semiorbicular de 2.0 $\mathrm{mm}$ de ancho en la base y $1.0 \mathrm{~mm}$ de largo; perianto trímero de $4.0 \mathrm{~mm}$ de 
largo, los lóbulos oblongos, profundos cerca de la base; androceo de hasta 3.0 mm. de alto; estigma sésil y oblicuo (Spichiger et al. 1989).

Fruto capsular, de $1.8 \mathrm{~cm}$. de alto por $2.3 \mathrm{~cm}$., de ancho; de paredes delgadas de 0.5-1.5 mm., línea de sutura muy prominente; pedúnculo de aproximadamente $4.0 \mathrm{~mm}$ de largo, consta de una sola semilla dos veces más ancha que alta.

Madera semidura, albura y duramén bien diferenciados; el primero blanco cremoso, predominante; duramen pardo; médula céntrica y sana. Grano recto, brillo y textura media; poros ligeramente visibles, solitarios o agrupados en filas radiales; parénquima paratraqueal terminal. Densidad media, resistencia mecánica baja a media, secado bueno y buen comportamiento a la máquina de carpintería. Su uso recomendado es en carpintería de obra, mobiliario en general y ebanistería (Baluarte y Aróstegui, 1991).

Esta especie habita en bosque primario no inundable, sobre suelos arcillosos, de topografía plana o levemente ondulada. Spichiger et al. (1984) y Encamación (1983); señalan que esta especie está distribuida en la cuenca amazónica brasileña, peruana y colombiana; también en la Guayana y en Venezuela.

A pesar de su amplia distribución presenta escasa regeneración natural encontrándose aisladamente. Una característica destacable que permite distinguir cualquier Miristicáceae (americana o de otras regiones) de otras familias de árboles, y su savia rojiza o amarillenta algo transparente que brota al cortar la corteza; sin embargo esta particularidad suele encontrarse en otros taxones como Pterocarpus de Leguminosae, Croton de Euphorbiácea y Unonopis de Anonacae; que habitan también en la Amazonía Peruana; pero difieren en alguna característica vegetativa que toda confusión sería imposible.

Qualea paraensis Ducke (gráfico 2).

Árbol dominante, cuatro raíces tablares prominentes en la base; fuste recto y cilíndrico, casi recto hasta la primera rama.

Corteza externa fisurada, marrón con manchas verdes; ritidoma coriáceo, estratificado que se desprende en placas rectangulares o irregularmente, en las ramas el ritidoma se desprende en escamas pequeñas. Corteza interna fibrosa arenosa, pardo rojizo, poco amargo, olor característico.

Ramita terminal circular, verdosa; yema terminal con hojitas conduplicadas, papirácea, color concho de vino, haz y envés lustroso.

Hojas simples, opuestas o ligeramente subopuestas, estipuladas. Peciolo fino, surcado; limbo glabro, coriáceo, aovado o elíptico con acumen largo y 
estrecho, ápex redondeado raramente emarginado; base obtusa o subaguda; nervio principal impreso en la haz, con pelos adpresos; nervios secundarios muy finos y numerosos, anastomasados, unidos entre ellos por un nervio marginal a 1 mm. del borde.

Inflorescencia paniculada, de 6-10 cm. de largo, terminales o situadas en la axila de las hojas superiores. Flor con pedicelos pubescentes y delgados; sépalo espolonado, sedoso-plateado, espolón oblongo, el resto del cáliz está compuesto de dos lobos laterales redondeados y de dos lobos anteriores más largas, más o menos pubescentes; pétalo blanco emarginado, con mancha purpúrea hacia la base y con la parte central amarilla; antera dorsifija, pubescente; estilo glabro, etigma semilateral; ovario hirsuto (Spichiger et al 1990).

Fruto: cápsula de $4.0-4.5 \mathrm{~cm}$. de largo por $2-2.5 \mathrm{~cm}$. de ancho, aovadoelípticas, finamente verrugosas, cortamente apiculadas triloculares, dehiscentes por tres valvas; cáliz persistente; pedúnculo de $7 \mathrm{~mm}$. de largo, espeso. Semillas aladas de $4 \mathrm{~cm}$. de largo.

Madera dura y pesada, albura cremoso-amarillenta, susceptible al ataque de hongos; duramen predominante, marrón oscuro, forma regular, anillos de crecimiento bien pronunciados, al contacto con el aire vira lentamente al anaranjado pálido; médula céntrica y sana. Grano recto y entrecruzado, textura media a gruesa, brillo medio o bajo, poros solitarios y múltiples radiales, parénquima paratraqueal. Densidad y resistencia mecánica alta, secado regular y mal comportamiento a las máquinas de carpintería, veteado llamativo. Uso recomendable en parquet, durmientes, pilotes, puentes y puntales, chapas decorativas, mangos de herramientas y piezas torneadas (Baluarte y Aróstegui, 1991). Los individuos jóvenes se usan como madera redonda para construcción (Vásquez, 1989).

Esta especie habita en bosque primario no inundable, sobre suelo arcilloso o arcillo-arenoso de topografía plana en la región Amazónica (Spichiger et al. 1990). Encarnación (1983), informa que también se lo encuentra en terrenos inundables; el autor de este documento encontró árboles de este género en zonas hidromórficas; pero la madera de estos últimos posee propiedades físicas diferentes a la especie de terrenos bien drenados especialmente lo referente a la densidad; razón por la que sospecha que los individuos de áreas inundables podrían tratarse de otra especie.

El árbol de esta especie en su fase arquitectural final cuenta con una exuberante copa de gran cobertura sobre cuya base suele observarse abundante regeneración natural que luego desaparece. 
Qualea trichanthera Warm. (gráfico 3).

Árbol dominante, raíces tablares delgadas, copa grande y esferoidal; fuste recto y cilíndrico, con nudos conspicuos a manera de hernias en toda su longitud. Corteza externa áspera y lenticelar, marrón oscuro, las lenticelas son agrupadas en filas transversales; ritidoma leñoso desprendible en escamas pequeñas. Corteza interna fibrosa, amarillo acentuado, olor característico y sabor dulzón, se oxida gradualmente al pardo claro; al día siguiente, de la entalladura de la corteza interna brotan mucílagos color caramelo.

Ramita terminal orbicular, en la parte superior más o menos rectangular, pubescentes cuando jóvenes, volviéndose glabro con el tiempo.

Hojas simples, opuestas o muy ligeramente sub-opuestas, coriácea; haz glabro y envés glabrescente; limbo elíptico, algunos oblongos; ápice caudado acuminado que termina en un mucrón de $1.0 \mathrm{~mm}$. de largo; pecíolo esbelto, finamente canaliculado, con presencia de una glándula en la unión de éste con la ramita; base redondeada, borde entero, nervio longitudinal impreso en la haz, pubescente y muy prominente en el envés, con dos alas pubescentes laterales, nervios secundarios muy numerosos y finos formando un ángulo casi recto con el nervio longitudinal y unidos por un nervio marginal, a menos de $1.00 \mathrm{~mm}$ del borde.

Inflorescencia racimosa, de 10-15 $\mathrm{cm}$. de largo, axilares o terminales. Flores con pedicelo delgado y pubescente; bráctea floral decurrente; botón floral pubescentes; caliz con dos sépalos anteriores triangulares, dos laterales y uno espolonado, pétalo blanco, rayado de rojo; estambre único; antera peluda basifija; ovario y parte inferior del estilo lanoso-plateado (Spichiger et al. 1990).

Fruto cápsula oblongo-elíptico, ligeramente arqueado, finalmente verrugoso, apiculado, trilocular de $2.5-3 \mathrm{~cm}$. de largo por $1.3 \mathrm{~cm}$. de ancho, dehiscencia por 3 valvas; pedúnculo de $7 \mathrm{~mm}$. de largo por $2 \mathrm{~mm}$. de ancho; cáliz caduco; semillas aladas de hasta $3 \mathrm{~cm}$. de largo.

Madera semidura, albura cremosa; duramen marrón oscuro, se oxida cambiando al cremoso amarillento.

Es muy apreciada como madera aserrada, Vásquez (1989) informa sobre el uso en construcción en general, los individuos con diámetros menores se emplean como madera redonda.

Esta especie habita en bosque primario no inundable, sobre suelos preferentemente arcillosos de topografía ondulada. Cuenta con una amplia distribución, encontrándolo en la región amazónica de Venezuela, Guayana, Colombia, Brasil y Perú (Spichiger et al. 1990).

Esta especie por la coloración de su madera fue considerada tradicionalmente como una Lauraceae, el epíteto vernáculo con que se le conoce 
es "moena sin olor", se lo encuentra registrado en los inventarios dentro del taxón antes mencionado.

En ausencia de flores, frecuentemente se lo confunde con la Qualea paraensis por la similitud de sus hojas, sin embargo, existen detalles vegetativos particulares que lo diferencian como son el mucrón del apex y la presencia de glándulas en la unión del pecíolo con la ramita.

De acuerdo a la clasificación de la venación foliar establecida por Hickey (1974); esta especie junto con la Qualea paraensis están incluidas dentro del grupo Camptódroma; empero, no podemos insertado en un subgrupo específico porque no se ajusta a ninguna clasificación precisa al respecto por su nerviación secundaria peculiar.

Tapirira guianensis Aublet (gráfico 4)

Árbol de porte mediano, ramificación alterna secuencial, ramas horizontales a erguidas; base del fuste con raíces tablares medianos seguido de un fuste recto de sección circular en toda su extensión con leve ahusamiento en la parte alta; copa cónica a globosa.

Corteza externa fisurada, rojo oscuro con manchas blancas, fisuras longitudinales axiales medianamente pronunciadas. La interna es laminar-fibrosa, estratificada, color rojo teja; exuda lentamente por toda la corteza interna escasas gotas de resma cremosoamarillenta, de consistencia mantecosa, olor característico y sabor insípido.

Ramita terminal cilíndrica, pubescente; yema terminal en forma de puño, cubierto por pulverulencia farinosa.

Follaje espeso a ralo, con hojas compuestas, alternas imparipinnadas, pecíolo pulvínulo, esbelto, comprimido y fino, color violáceo. Foliolos opuestos, decurrentes en su base, basalmente agudo, asimétrico; limbo coriáceo a sub coriáceo, borde entero, ápice caudadoacuminado; haz con nervio medial y laterales poco notorios, broquidódromos.

Inflorescencias: Tirsos de 10-15 cm. de longitud, terminales o en la axila de las hojas terminales. Flor masculina con perianto pentámero, caliz gamosépalo aplastado, pétalos libres, diez estambres, ginecéo atrofiado. Flor femenina con diez estambres (Spichiger et al. 1990).

Fruto globoso, drupáceo de $13 \mathrm{~mm}$. de largo y $10 \mathrm{~mm}$. de diámetro, consta de una sola semilla envuelta de un epicarpio fino.

Madera sumamente blanda y liviana, albura y duramen no diferenciables, ambos cremosos, al cabo de cierto tiempo se oxida al pardo claro. La madera aserrada exuda una sustancia mantecosa, grisácea, inodora e insípida.

Es utilizado frecuentemente para vigas, caibros y ripas. En la industria del mueble se recomienda su uso en acabados internos, molduras, mesas comunes; 
también se utiliza para embalaje y cajonería en general, juguetes; tacos de zapatos, tamancos y piezas torneadas como objetos de adornos, patas de muebles, hormas de zapatos y mangos de herramientas. En la industria de la transformación de la madera se utiliza para chapas decorativas, palitos de fósforos y lápices, en la industria de la construcción se utiliza en encofrados (documento anónimo y sin fecha de publicación).

Regenera por semillas en forma más o menos abundante. Árbol muy frecuente, bien distribuido, se lo encuentra en la sucesión pionera a secundaria temprana, asociación heterogénea, heliófito a semiheliófito; es atacado por defoliadores (Mahecha, citado por Mahecha, Rodríguez y Acero; 1984).

Crece sobre suelos arcillosos de topografía plana o levemente ondulada de la región amazónica.

\section{Vantanea parviflora Lam (gráfico 5)}

Árbol dominante, robusto, base del fuste con raíces tablares prominentes y delgadas, fuste recto y cilíndrico con marcada presencia de anillos; copa grande con espeso follaje.

Corteza externa pardo amarronado, con lenticelas en filas longitudinales; ritidoma leñoso que se desprende en tiras largas de variadas dimensiones. La interna es fibrosa, rojizo con jaspes longitudinales amarillos, sabor amargo y olor característico; exuda lentamente escasa resma cristalina, pegajosa que se oxida al color rojo sangre con sabor astringente y olor característico.

Ramita terminal orbicular, verdes, con tricomas hirsutos y yemas terminales con pubescencia cremosa.

Hojas simples, alternas, coriáceas; haz y envés glabros; limbo de forma obovado a casi eliptico, borde entero y ciliado; pecíolo poco engrosado en la base; base aguda y decurrente; nervio principal prominente en las dos caras, nervios secundarios impresos en la haz y ligeramente prominente en el envés.

Inflorescencia terminal o axilar; cimas compuestas de tipo corimbiforme. Flores glabras, cáliz gamosépalo, corola de prefoliación valvar y capullo frecuentemente torcido, cinco pétalos lineares, estambres muy numerosos, ovario glabro y ovoide (Spichiger et al. 1990).

Fruto drupa elipsoidal, exocarpo rugoso de unos 5.0-7.0 $\mathrm{cm}$. de largo poro 4.0-5.0 de ancho.

Madera pesada y dura, albura marrón claro; duramen regular, predominante, marrón oscuro; médula céntrica y sana; sumamente resistente al aserrío. 
Debido a las características peculiares de la madera, los nativos la utilizan para horcones de viviendas, sinchinas para cercos, largueros de puentes y postes.

Esta especie habita en bosque primario no inundable de terrenos ondulados, sobre suelos arcillosos. Spichiger et al. (1990) indican que este género está distribuido en bosques de Guayana Francesa, en los estados brasileños de Pará y Amazonas y estado de Amazonas en Venezuela. Debajo del árbol se observa escasa regeneración natural.

\section{BIBLIOGRAFIA}

BALUARTE Y AROSTEGUI, 1991. "Usos probables de las maderas de 20 especies del Departamento de Loreto", en Folia Amazónica. Perú. Vol. 3: $61-81$.

ENCARNACION, F. 1983. "Nomenclatura de las especies forestales comunes en el Perú". Documento de trabajo $\mathrm{N}^{\circ}$ 7. Proyecto PNUD/FAO/PER/81/002. Lima. 149 p.

HICKEY, L. 1974. "Clasificación de la arquitectura de las hojas de dicotiledóneas. en Boletín de la Sociedad Argentina de Botánica. Vol XVI ( $\left.\mathrm{N}^{\mathrm{o}} 1-2\right)$ : 1-26.

HOLDRIDGE, L. 1987. Ecología basada en zonas de vida. IICA (Instituto Interamericano de Cooperación para la Agricultura) Tercera reimpresión. San José, Costa Rica, 216 p.

MAHECHA, G., RODRIGUEZ, R. Y ACERO L. 1984. Estudio dendrológico de Colombia. Universidad Distrital "Francisco José de Caldas", Instituto Geográfico “Agustín Codazzi”. Bogotá. 282. p.

MARENGO, 3. 1983. "Estudio agroclimático en la zona de Jenaro Herrera (Requena-Loreto) y climático en selva baja Noreste del Perú". Tesis Ing. Meteorólogo-UNA-La Molina.Lima. 440 p.

PERU, OFICINA NACIONAL DE EVALUACION DE RECURSOS NATURALES. 1976. Mapa ecológico del Perú (gofa explicativa). Lima. $196 \mathrm{p}$. 
RIOS, J. 1982. Prácticas de dendrología Tropical. Departamento de Manejo Forestal: UNA - La Molina. Lima. 150 p.

SABOGAL, C. 1980. "Estudio de caracterización ecológico silvicultural del bosque "copal", Jenaro Herrera (Loreto-Perú)'. Tesis Ingeniero Forestal. UNA - La Molina. Lima. 466 p.

SPICHIGER, R. 1982. "Prueba de clave para reconocer, a partir de los órganos vegetativos, las principales familias de árboles de una reserva natural de la Amazonía Peruana”. Societé Botanique de Géneve, Suiza. Saussurea (Suiza) 13:1-16.

SPICHIGER, R. et al. 1989. contribución a la flora de la Amazonía Peruana; los árboles del arboretum Jenaro Herrera. Vol. 1 Conservatorio y Jardín Botánicos de Ginebra/COTESU/IIAP. Ginebra, Suiza. 359.

SPICHIGER, R. et al. 1990. Contribución a la flora de la Amazonía Peruana; los árboles del arboretum Jenaro Herrera. Vol. 2. Conservatorio y Jardín Botánicos de Ginebra/COTESU/IIAP. Ginebra, Suiza. 565 p.

UNITED NATIONS EDUCATIONAL, SCIENTIFIC and CULTURAL ORGANIZATION - UNESCO. 1981. Mapa de la vegetación de América del Sur (nota explicativa) París. 189 p.

VASQUEZ, R. 1989. Plantas útiles de la Amazonía Peruana. Iquitos, Perú. 195 p. 


\section{Grafico 1}

Osteophloeum platyspermum (A.DC) Warb. a) ramita con inflorescencia , b) flor y androceo; c) ramita con inflorescencias (Bernardi 16316); d) flor y gineceo. (Warburg 9060); e) ramita con frutos. (Tomado de Spichiger 8c al.; Contribución a la flora de la Amazonía Peruana Vol.1)

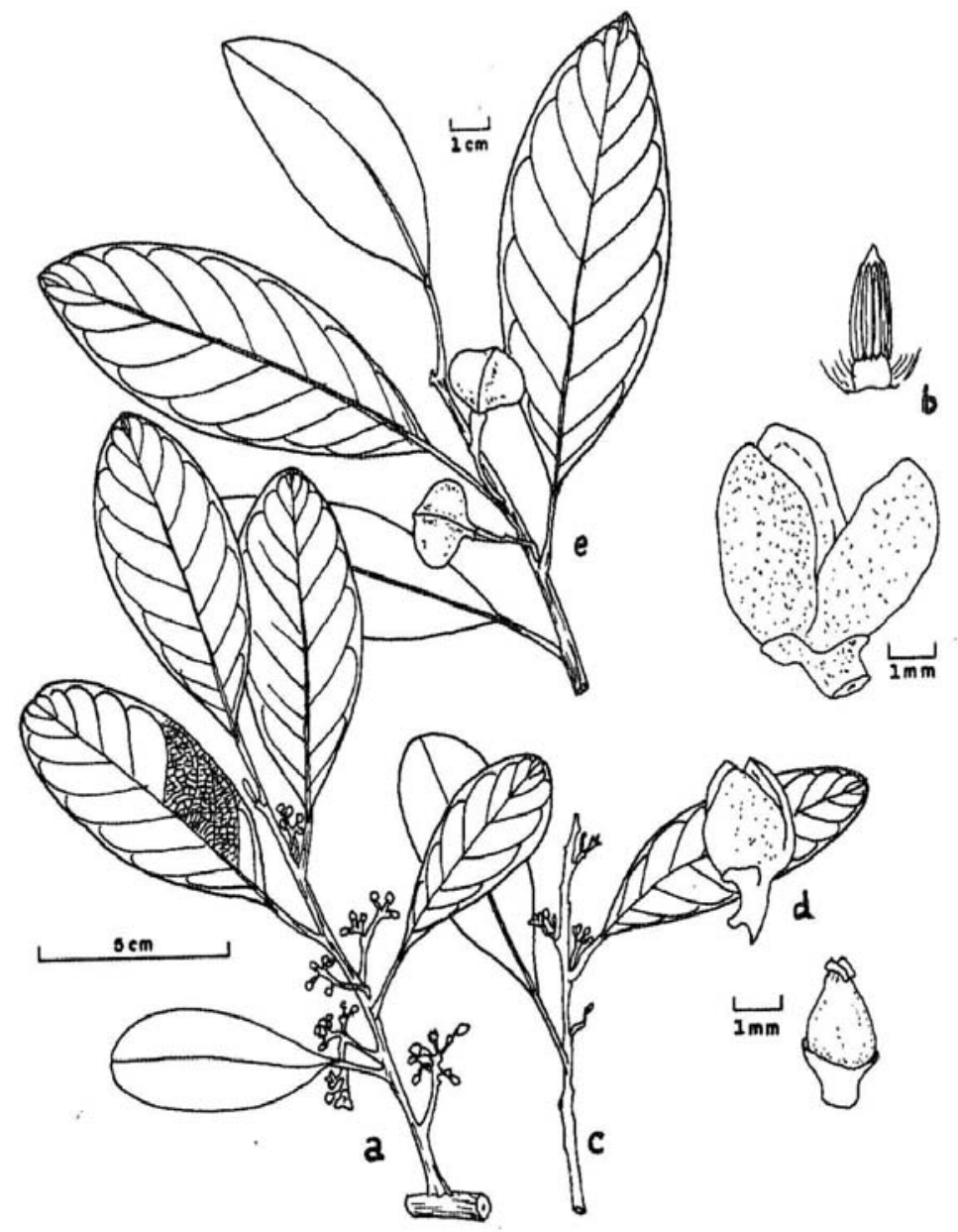




\section{Gráfico 2}

Qualea paraensis Ducke

a) ramita florífera; b) estípulas; c) flor; $\mathrm{c}^{1}$ ) pétalo; d) ramita fructífera (Tomado de

Spichiger 8c al.; Contribución a la flora de la Amazonía Peruana Vol.2)

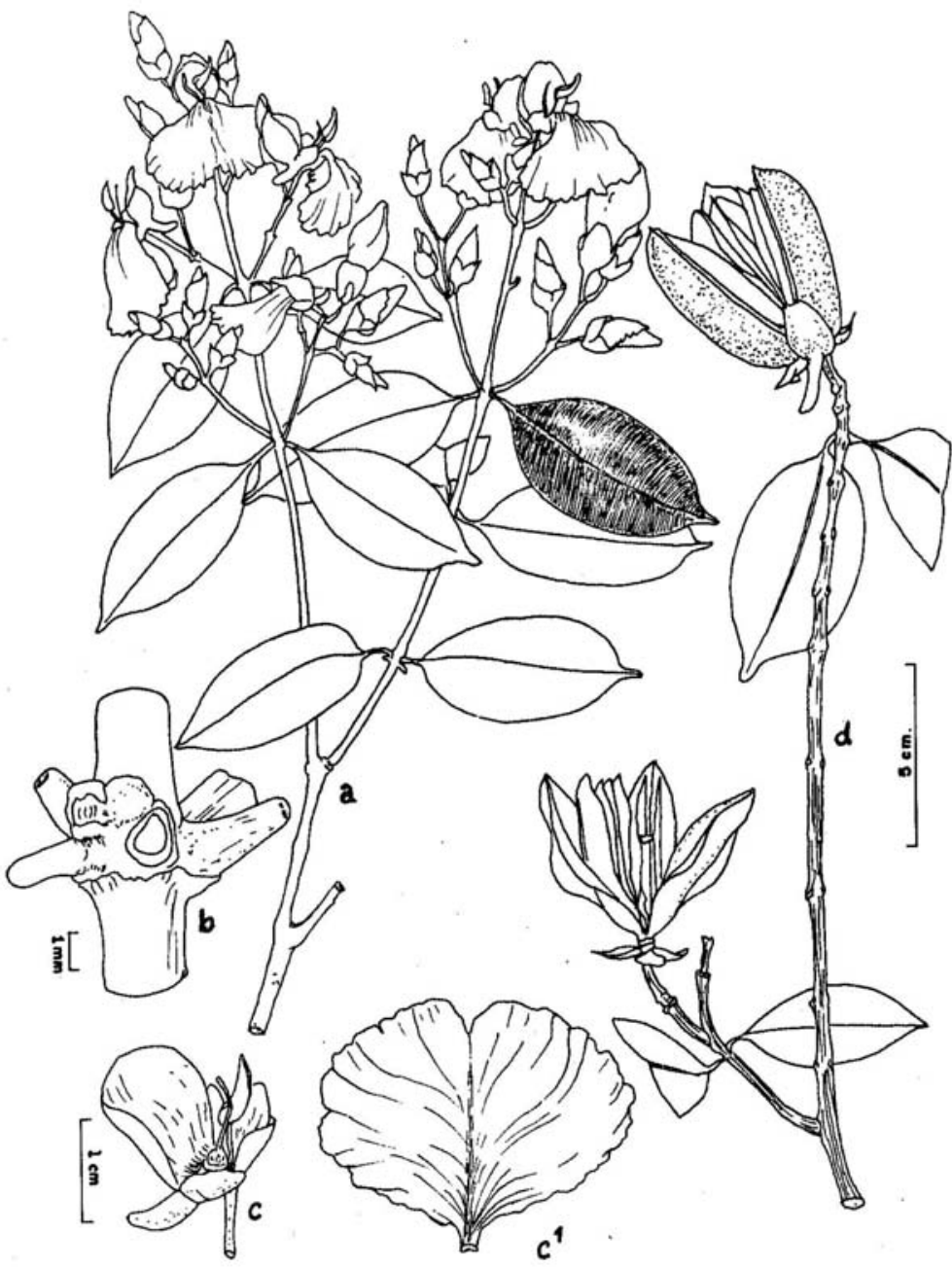




\section{Gráfico 3}

Qualea trichanthera Warm.

a) ramita florífera; b) estípullar; c) flor; $\mathrm{c}^{1}$ ) pétalo; d) ramita fructífera. (Tomado de Spichiger 8c al.; Contribución a la flora de la Amazonía Peruana Vol. 2

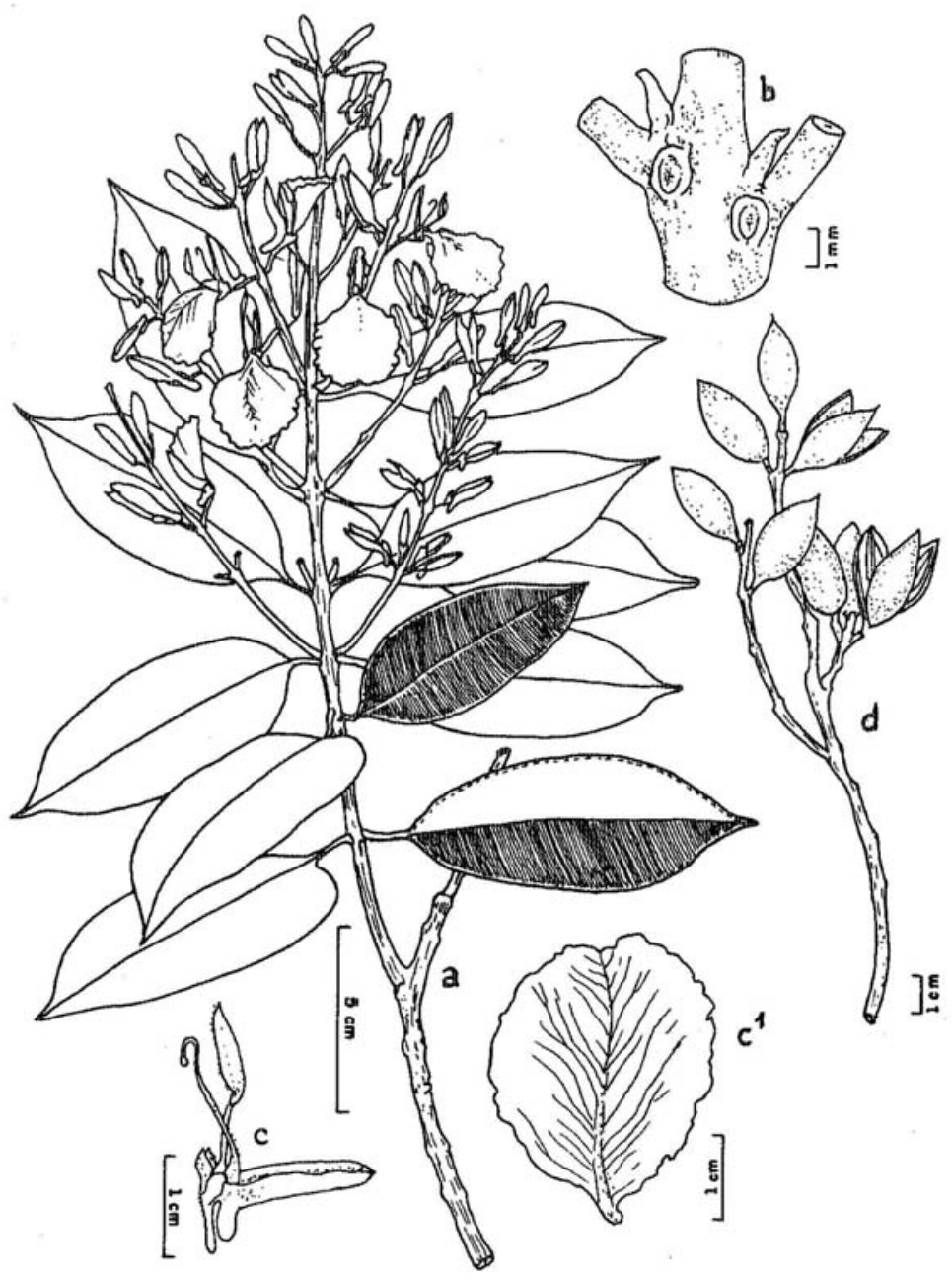




\section{Gráfico 4}

Tapirira guianensis Aublet

a) ramita e infrutescencias; b) inflorescencias; c) flor; d) ovario, corte longitud; e) detalle del disco. (Aronson \& Jarámillo 25784): f) flor (tomado de Spichiger 8c al.; Contribución a la flora de la Amazonía Peruana Vol.2)

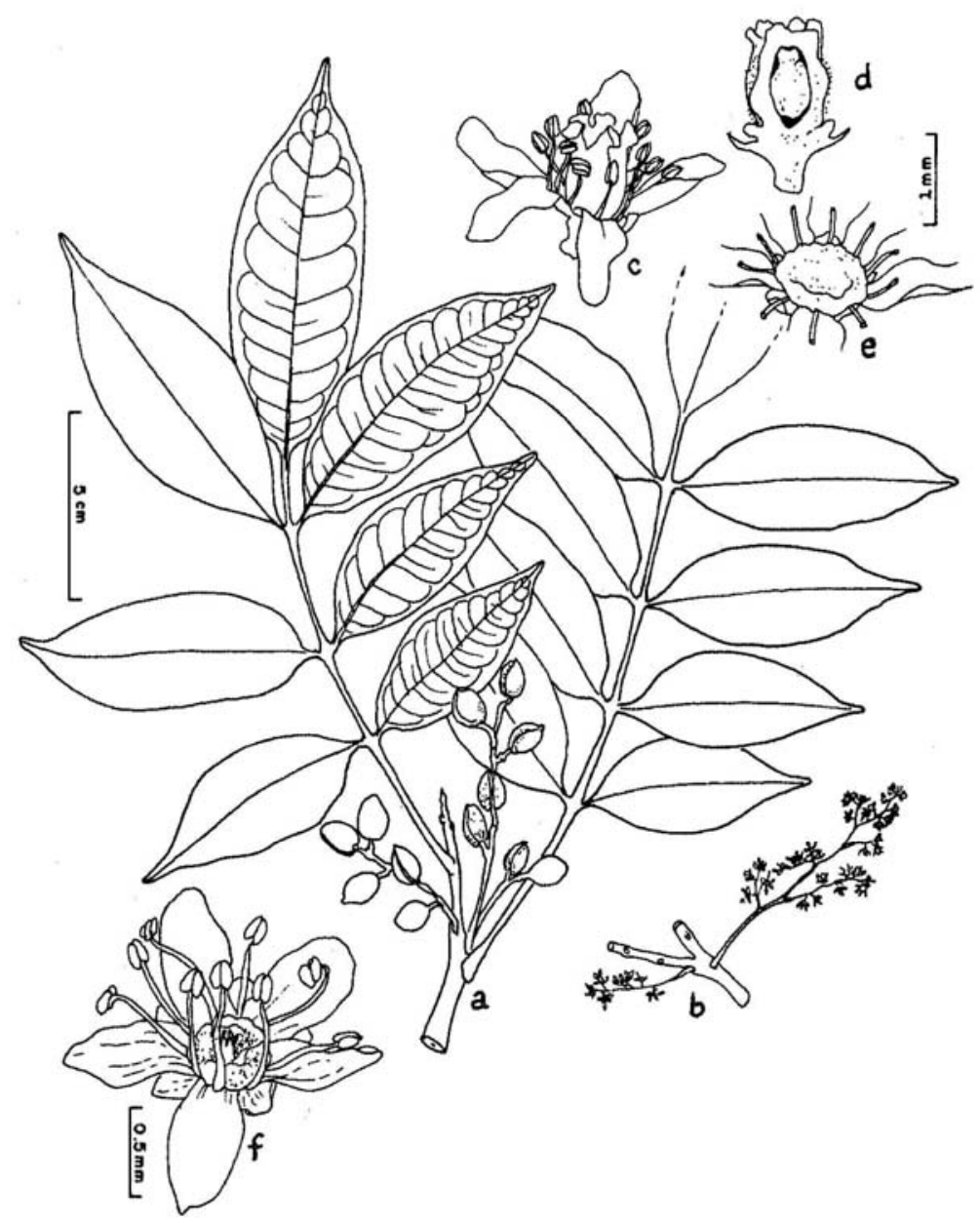




\section{Gráfico 5}

Vantanea parviflora Lam.

a) ramita florífera; b) flor; c) ápice de estambre; d) gineceo. e) fruto; f) endocarpo. (tomado de Spichiger 8c al.; Contribución a la flora de la Amazonía Peruana Vol.2)

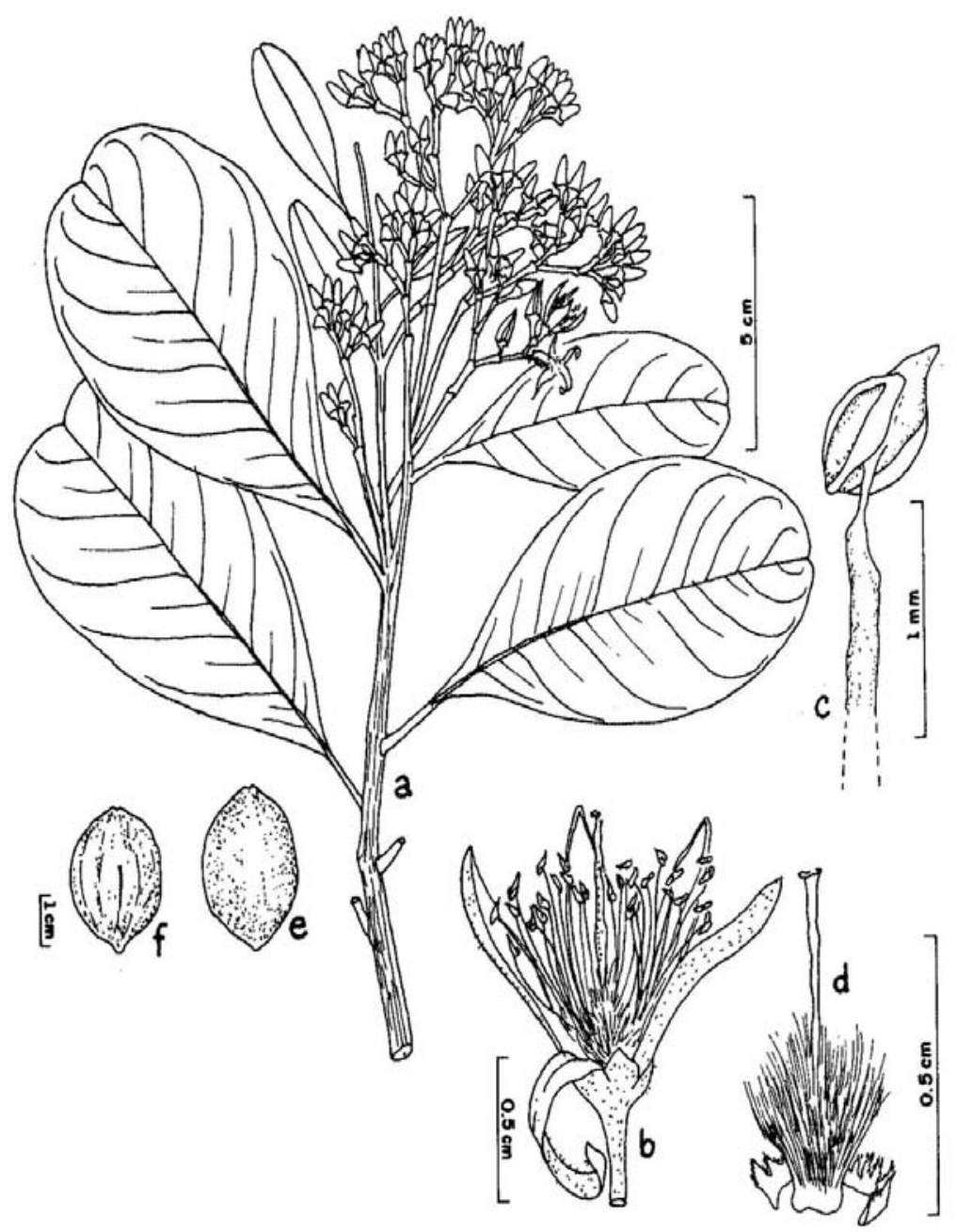

